\title{
The Effect of Constructive Play Therapy on Anxiety Levels of Preschool Children Due to Hospitalization
}

\author{
Nurwulansari ${ }^{1}$, Maria Ulfah Ashar $^{2}$, Huriati $^{3}$, Sysnawati Syarif ${ }^{4}$ \\ ${ }^{1}$ Nursing Department, Faculty of Medical and Health Science, Alauddin Islamic State University, Makassar, Indonesia \\ 2 Department of Magical Surgical Nursing, Faculty of Medical and Health Science, Alauddin Islamic State University, \\ Makassar, Indonesia \\ 3 Department of Child Nursing, Faculty of Medical and Health Science, Alauddin Islamic State University, Makassar, \\ Indonesia \\ 4 Department of Mental Health Nursing, Faculty of Medical and Health Science, Alauddin Islamic State University, \\ Makassar, Indonesia \\ nurwulansariilham@gmail.com \\ DOI: http://doi.org/10.29080/jhsp.v3i3S.282
}

\section{Keywords \\ Constructive play; \\ Therapy; \\ Anxiety level; \\ Preschool child.}

\begin{abstract}
During the hospitalization process, the child will show anxiety due to unfamiliar environmental factors, lack of freedom in activities, and lack of emotional support. Continual anxiety will cause a decrease in the immune system so that it accelerates the occurrence of disease complications during treatment and slows down the recovery process. The focus of nursing intervention that is done is to minimize anxiety by providing psychological support to children through the provision of constructive play therapy. The aim if this research is to determine the effect of constructive play therapy towards the anxiety level of preschool children due to hospitalization. The research design used in this study was Pre-experiment with a one-group pre-post test design. Data collection using preschool anxiety scale (PAS) questionnaire. The sample in this study were 30 respondents selected by using accidental sampling technique. Based on the results of the Wilcoxon Test analysis, the mean value of pre-test 36.57 and post-test 28.23 and the value of $p=0.0001<0.05$. Meaning that there is an effect of constructive play therapy on the level of anxiety in preschool children with the treatment of constructive play therapy your child who easily communicate the right feeling of anxiety during in the hospitalization, so that the anxiety experienced can be decreased. Constructive play therapy can reduce response anxiety in preschool children who experience hospitalization. Therefore, it is recommended to the hospital and nurses to be able to apply constructive play therapy. as one of the interventions to minimize the impact of hospitalization.
\end{abstract}

\section{Introduction}

The United Nations Children's Fund (UNICEF) (2012) states that the prevalence of children undergoing hospital care is around 84\% [1]. Disease Control, National Hospital Discharge Survey (NHDS) (2004) in Apriliawati (2011) explained that more than 1.6 million children, including 2-6 years old undergo hospitalization due to injury and various other causes [2]. Kain (2006) in Apriliawati (2011) also stated the results of his survey that in the United States, it is estimated that more than 5 million children undergo hospitalization due to surgical procedures and more than $50 \%$ of these children experience anxiety and stress [2]

The number of the child population in Indonesia is $82,840,600$ children from $245,569,381$ inhabitants. National Health Survey (SUSENAS) also explains the number of preschoolers in Indonesia by $72 \%$ of the total population of Indonesia, and it is estimated that 35 per 100 children undergo hospitalization and $45 \%$ of them experience anxiety [3]. In addition to requiring special care compared to 
other patients, the time needed to treat child sufferers is $20 \%-45 \%$ over time to treat adults. Children who are hospitalized will affect their physical condition and psychology.

The Ministry of Health of the Republic of Indonesia (KEMENKES RI) (2015) states the results of its survey are based on the child morbidity in Indonesia according to the age group 0-2 years by $15.14 \%$, age 3-5 years by $25.8 \%$, age $6-12$ years by $13,91 \%$ if calculated from the total population. It can be concluded that the highest preschool child morbidity rate is $25.8 \%$ [4] . Based on the results of a maternal and child health survey in 2010, data from 1,425 children experienced the impact of hospitalization, and $33.2 \%$ experienced severe hospitalization impacts, $41.6 \%$ experienced the impact of moderate hospitalization, and $25.2 \%$ experienced the impact of mild hospitalization [5].

Preschoolers have a great opportunity to experience health problems because their immune response and defense strength are not optimal. Children who are sick and have to be hospitalized can experience unpleasant experiences. This can lead to various responses to the experience of hospitalization. Some treatment measures can cause psychological problems including emotional, cognitive, and social prolems. Typical problems that arise are fear, anger, pain, and anxiety [6].

Anxiety due to separation or commonly called analytic depression, is a major stress in infants from middle to preschool age. At this age, range anxiety is manifested in three phases, namely the phase of protest, despair, and release. During the protest phase, children react aggressively, reject attention from others, and their grief cannot be calmed. During the desperate phase, children tend to be inactive, not interested, and withdraw from others. While the release phase, the child will appear to adapt to the environment, but this is a sign of resignation [7].

Anxiety cannot be interpreted directly as an illness, but rather a symptom. Children will show many stages of anxiety behavior due to hospitalization, although in general, the behavior they exhibit is more vaguer and passive. Children show anxiety by refusing to eat, having difficulty falling asleep, crying, withdrawing from others, and refusing to cooperate with medical personnel when they are given treatment measures that will make the child's condition worse [8]. Continuous anxiety will cause a decrease in the immune system, thus accelerating the occurrence of disease complications during treatment and slowing down the recovery process [9]

To reduce anxiety in children undergoing hospitalization can be given intervention in the form of relaxation, music therapy, physical activity, art therapy and play therapy [10]. Based on the most prominent developmental tasks in preschool children, namely fine motor development, therefore, for children to reach and pass through the stages of development and growth optimally, appropriate stimulation is needed according to their age [11]. In accordance with the stage of development of play for children aged 3-6 years, the game that can be done is constructive play. In this playing activity, the child will create something, create a particular building with the available game tools. For example, making houses with wooden beams or with leggo pieces, drawing, arranging wooden pieces with pictures, and making shapes using plasticine or play dough [12]. So, this constructive game can increase pleasure and satisfaction to overcome the anxiety experienced due to hospitalization, because constructive play therapy does not require large energy to play, so it does not interfere with the child's health recovery process [13].

Based on preliminary studies that have been carried out in Syekh Yusuf District Hospital of Gowa Regency, data was obtained that in 2017, there were 1964 children who experienced a hospitalization, as many as 316 children aged 3-6 years. From these data, it can be seen that the morbidity rate of children who experience hospitalization is very high. Based on the results of interviews conducted with one of the nurses in the childcare room at Syekh Yusuf District Hospital of Gowa Regency, data was obtained that children who were hospitalized often cried and shouted for help to parents when infusion and blood samples are taken, even the child does not want to be touched by a health worker if he is to be given treatment.

Based on this description, therefore, the researchers feel the need to take action to mitigate the anxiety of preschoolers who experience hospitalization by giving constructive play therapy (arranging blocks).

\section{Methods}

This research uses pre-experimental research with pre and post-test without control group design. This research was carried out on 9-30 July 2018. The population in this study was every subject who fulfilled the characteristics of preschoolers who were being treated in the inpatient room of Syekh Yusuf District Hospital of Gowa Regency. The technique used is accidental sampling, which is the method of taking samples that are accidentally met or have a willing to comply with the following criteria which is Inclusion that include; a. Children who are self-conscious (composmentis), b. Children are willing to become research respondents, c. Children who are treated are 3-6 years old, $d$. Children and parents can be invited to communicate verbally and e. Children want to participate in play therapy activities from beginning to end. Exclusion criteria include; a. Children with mental retardation or children with 
attention-deficit and hyperactivity disorders, b. Decreased awareness, and c. 24-hour postoperative patients.

Data collection methods in this study used a modified questionnaire consisting of 26 questions as a measure of anxiety level in preschoolers due to hospitalization in Syekh Yusuf District Hospital of Gowa Regency. The instrument used is Spance Preschool Anxiety Scale (SPAS) which was adopted from Ilmiasih, which has been tested for validity and reliability. This scale is filled by parents of children by following the instructions on the instrument sheet, parents will report what happens to their children based on the questions that exist on the scale [13]. The maximum number of scores on the SPAS anxiety scale is 112 , but what will be used in this study consists of only 26 questions with a maximum score of 104 . Respondents were asked to show the frequency of each symptom, there are four scales starting from never (score 0), rarely (score 1), sometimes (score 2), often (score 3) and very often (score 4). The total results of the questionnaire score will be the criteria for children's anxiety levels, with the following anxiety score ranges: mild (score <26), moderate (score 26-52), weight (score 53-78), and very heavy / panic (score> 79) This instrument consists of 5 subscales namely general anxiety, social anxiety, obsessive-compulsive disorder, fear of physical injury and separation anxiety [14].

Data analysis in this study used a univariate analysis with the aim to get an overview of frequency distribution and perform bivariate analysis to see the relationship between the two significant variables or not. The test used was Wilcoxon test.

\section{Results}

Table 1. Distribution of Frequency of Respondents by Age Gender, Length of day Treated and Experience of Treated in the Child Care Room of Syekh Yusuf District Hospital of Gowa Regency on 9-30 July 2018

\begin{tabular}{ccccc}
\hline \multicolumn{2}{c}{ Type of Respondents } & Frequency (n) & Percentage & $\begin{array}{c}p- \\
\text { value }\end{array}$ \\
\hline \multirow{2}{*}{ Child's age } & 3 & 7 & $23,3(\%)$ & 0,000 \\
(Year) & 4 & 10 & $33,3(\%)$ & 1 \\
& 5 & 8 & $26,7(\%)$ & $16,7(\%)$ \\
\hline \multirow{2}{*}{ Gender } & 6 & 5 & $100(\%)$ & 0,6 \\
& Total & 30 & $56,7(\%)$ & 0,8 \\
\hline \multirow{2}{*}{ Length of the } & Male & 17 & $43,3(\%)$ & $100(\%)$ \\
day treated & Total & 13 & $70(\%)$ & $30(\%)$ \\
\hline \multirow{2}{*}{$\begin{array}{c}\text { Experience } \\
\text { of treated }\end{array}$} & Have been treated & 30 & $100(\%)$ & 0,001 \\
\hline
\end{tabular}

Source: Primary data (2018)

Table 2. Distribution of Frequency of Respondents Based on Anxiety Response Before and After Constructive Play Therapy in the Children's Care Room Syekh Yusuf District Hospital of Gowa Regency on 9-30 July 2018

\begin{tabular}{ccccc}
\hline Anxiety level & \multicolumn{3}{c}{ Pre-test } & \multicolumn{2}{c}{ Post-test } \\
\cline { 2 - 5 } Mild & $\mathrm{N}$ & $\%$ & 10 & 33,3 \\
Moderate & 6 & 20 & 20 & \\
Heavy & 21 & 70 & 0 & 0 \\
Total & 3 & 10 & 30 & 100 \\
\hline
\end{tabular}

Source: Primary data (2018)

Table 3. Analysis of the Effect of Constructive Playing Therapy on Anxiety Response in Children's Care Room Syekh Yusuf District Hospital of Gowa Regency on 9-30 July 2018

\begin{tabular}{cccccc}
\hline $\begin{array}{c}\text { Anxiety } \\
\text { Level }\end{array}$ & Mean & Std.Deviation & Min & Max & p-Value \\
\hline Pre-test & 36,57 & 11,069 & 21 & 59 & 0,0001 \\
Post-test & 28,23 & 8,846 & 16 & 50 & \\
\hline
\end{tabular}

Source: Primary Data (2018) 


\section{Discussion}

Based on the Table 3.1 about Age distribution, it is shown that the most respondents are children aged 4 years and obtained a value of $p=0.0001$, meaning that the value of $p$ is smaller than $\alpha(0.05)$ it shows there is a significant relationship between age and anxiety level of children treated in hospital. According to Supartini (2014), the child's reaction to pain varies according to the level of child development [15]. The younger the child is, the harder it will be to control his emotions and the harder it will be for him to adjust to the environment in the hospital [16]. The stage of cognitive development of preschoolers is to have an egocentric mindset and magical thinking. Egocentric thinking patterns where children focus on themselves so that it is difficult to pay attention to the surrounding environment. Magical thinking patterns in the development of preschoolers can be used to play therapy to play the type of fantasy game so that the child is distracted and can help reduce anxiety. This can also be used to help child egocentric so that attention can be diverted to this type of fantasy game, for example by playing simple tricks. Nurses need to pay attention to the stage of child development so as to enable an increase in the success of interventions in helping to reduce children's anxiety [17].

From the same data, it is shown that children who become respondents are mostly male and obtained $p=0.6$, meaning that the value of $p$ is greater than $\alpha(0.05)$ it shows there is no significant relationship between gender and anxiety level children who are hospitalized. At the age of 3-6 years anxiety, is more common in girls than boys, this is influenced by cultural factors and hormonal factors that differ between men and women. In addition boys are also more active and explorative while girls use feelings more, are less patient and cry easily [18].

In terms of length of day treated, the average number of days of care in this study was 2 days and obtained $p=0.5$, meaning that the $p$-value greater than $\alpha(0.05)$ which showed no significant relationship between the length of the day of treatment and the level of anxiety of children who were hospitalized. Children who are hospitalized for more than 2 days still experience anxiety [20]. Children who are treated for long periods of time will affect behavior change, children who are treated for more than 2-3 days are more at risk of changes in anxiety compared to children who undergo treatment for more than 4 days. While children who get 1-day treatment will be at risk for changes in behavior after discharge from the hospital [19].

Meanwhile, regarding with experience of treated, it is found that children who are respondents mostly have experience of being hospitalized and obtained a value of $p=0.02$ meaning .that the $p$-value is smaller than $\alpha$ (0.05). It shows that there is a significant relationship between the experience of being hospitalized with anxiety levels of children hospitalized. The experience of the child treated before will make the child's experience base to perceive the next treatment. Children who have previously been treated in hospital have more aggressive behavior than children who have never been treated before. Children who have a history of previous treatment also often have many somatic complaints compared to children who have never been treated before. Children who experience hospitalization more than 2 times will tend to exhibit somatic symptoms, dependence, aggression, and show hyperactive behavior than children who have one-time experience. Children who have an unpleasant hospitalization experience cause children to be afraid and traumatized so that children will find it difficult to adapt to the hospital environment and are not cooperative towards action [20].

In the table 3.2 there are 6 children who experience mild anxiety, 21 children experience moderate anxiety and 3 children who experience severe anxiety. This proves that children who are hospitalized experience the impact of hospitalization in the form of anxiety. Anxiety is the most common feeling experienced by children when going to health care facilities. Child's anxiety response depends on the stage of the child's age. Child anxiety due to stress caused by the situation while undergoing treatment will have an impact on the child's cooperative level of treatment and care given if not overcome one of them by playing therapy [21].

Hospitalization in pediatric patients can cause anxiety and stress at all age levels. The main anxiety experienced can be in the form of separation from family, loss of control, loss of independence and freedom [22]. Long-term hospitalization with an inefficient environment identified can lead to changes in children's emotional and intellectual development. Children who usually get poor treatment during treatment, not only have less optimal development and physical growth, but also experience severe disorders of psychological status. In preschool children, the greatest anxiety experienced is when the child first enters the hospital. Children will experience high anxiety when he is hospitalized. It is likely that 
children will experience disorders for eating and sleeping, regressive behavior, aggressive behavior, irritability, and negativism [23].

The child's response to non-painful actions is the same as a response to a very painful action, if an examination of the ear, mouth, or temperature in the anus will make the child become very anxious. Children will respond to pain by wrinkling their faces, crying, closing their teeth, biting their lips, opening their eyes wide, asking their parents for help, or taking aggressive actions, such as biting, kicking, or hitting. Children who experience anxiety will affect the healing process because under stress conditions, there is suppression of the immune system so that patients who experience mental shock will be susceptible to disease. Based on the concept of psychoneuroimmunology, the hypothalamic process of the adrenal pituitary, it is said that psychological anxiety will affect the hypothalamus, then the hypothalamus will affect the pituitary, so that the pituitary will express ACTH (Adrenal Cortico Tropic Hormone) which can eventually affect the adrenal glands that produce cortisol. If the anxiety experienced by the patient is very heavy, the adrenal gland will produce cortisol in large quantities so that it can suppress the immune system [24]. It is this suppression of the immune system that will result in obstacles to the healing process. These results in longer treatment times require more treatment costs, even with suppression of the immune system will accelerate the occurrence of complications during treatment.

Based on table 3.3 Wilcoxon Test, analysis shows that the anxiety level of pre-test and post-test gives very significant results as indicated by the value of $p=0.0001$ smaller than $\alpha(0.05)$, meaning that there is influence of constructive play therapy on the level of anxiety in children of age preschool due to hospitalization. After being given constructive play therapy, the child will easily express feelings through playing and be able to eliminate fear in the hospital Through playing, activities children can get pleasure [25] . The pleasure obtained by this child is proven to reduce anxiety in children and can affect children's readiness when nursing actions are performed and provide healing for children who experience emotional disturbances. If the child understands about illness, separation, and bodily injury while the child is cared for, then it is expected that by giving play therapy, it can reduce the threat to the integrity and anxiety experienced by the child. With the reduced threat of physical integrity, it will reduce the stimulation of the autonomic nerves to release adrenaline so that the physical and psychological response to anxiety will decrease. To provide calmness and pleasure to the child the nurse can provide constructive attention when performing nursing actions or in a time contract. Constructive play therapy is an alternative for hospitals to do because it is tailored to the needs and development of children. Games in children in the hospital will not only give children a sense of pleasure, but also will help children express anxiety, fear, sadness, tension, pain, and thoughts that will make children more cooperative towards the given nursing actions, so the child becomes more comfortable so that it can reduce the length of stay in the hospital and can speed up the healing process.

Playing according to essay on laught explains that play therapy can change a person's behavior to laugh. Laughter indicates a person's emotional overflow when he enjoys playing. Playing that is done with or without using a tool will give a child's pleasure and imagination. This is one of the effective ways to overcome the impact of hospitalization on children because playing can increase the hormone endorphine in a person so that it can re-stabilize the hormone cortisol which affects the level of stress in a person.

According to Haruyama (2011), the hormone endorphine is a hormone produced by the part of the hypothalamus in the brain. This hormone can cause the muscles to relax, the immune system increases and the level of oxygen in the blood rises so as to make patients tend to be sleepy and can rest in peace [26] .This, hormone can also strengthen the immune system to fight infection and is known as morphine in the body which causes a healthy and comfortable sensation effect. In addition to removing the hormone endorphine, the body also secretes GABA (Gamma Amino Butric Acid) and Enkephalin. This substance can cause sleep, appetite, sensory perception, regulating body temperature, mood and retaining pain so that the pain felt by a sick child can be reduced or eliminated. If the stressor experienced by a child can be overcome then the anxiety experienced can decrease [26].

Therefore, to overcome the level of anxiety in children, the role of nurses in providing maximum nursing care is needed, one of them is by providing constructive play games to improve the welfare of patients. Children who are treated in a child care room it is very important to be given a game, so that child patients, besides being happy with the game, his mind also became peaceful. Based on Psychoanalytic Theory, Freud said that play serves to express an exclusive urge as a way to reduce excessive anxiety in children. The form of playing activity shown in the form of playing fantasy and 
imagination in socio darma or when playing alone. According to Freud (1920), through playing and fantasizing, children can express hopes and conflicts and experiences that cannot be realized in real life [27]. Seeing the phenomena and facts that occur in the location it is clear that there is an effect of constructive play therapy on the anxiety level of preschoolers who experience hospitalization.

\section{Conclusion and Suggestion}

Before being given constructive play therapy, the mean value was 36.57 , then after being given play therapy the mean value was 28.23 , so that it could be concluded that there was a therapeutic effect on constructive play therapy on the anxiety response of preschoolers in Children's Care Room Syekh Yusuf District Hospital of Gowa Regency, is the response to child anxiety decreases after being given constructive play therapy. This is because children can socialize and adapt in the child-care room.

\section{Reference}

[1] United Nations Children's Fund (UNICEF). Http://www.unicef.org/dprk/unicef-factsheet. 2012.

[2] Apriliawati, A. The Influence of Bibliotherapy on the Anxiety Level of School-Age Children Undergoing Hospitalization at the Jakarta Islamic Hospital. Thesis. Depok: Faculty of Nursing Science Master of Nursing Program, University of Indonesia. 2011.

[3] National Health Survey (SUSENAS). The number of preschoolers in Indonesia. 2010.

[4] RI Ministry of Health. Secretariat General of the Indonesian Health Profile (Health Statistics). Jakarta: KEMENKES RI. 2015.

[5] Nurhayati. An Overview of Anxiety in Preschoolers Conducted Therapy for Storytelling in the Nusa Indah Room Bhakti Wira Tamtama Hospital Semarang. Thesis. Faculty of Nursing Masters. Muhammadiyah University Semarang. 2013.

[6] Tesaningrum, Z. Effect of Lego play therapy on anxiety levels of preschoolers who have undergone hospitalisas in the Melati Room of RA Kartini General Hospital. Essay. Muhammadiyah University Semarang. Vol 1. 2013.

[7] Hockenberry, M.J., \& Wilson, D. Wong's essentials of pediatric nursing (9th ED). St. Louis: Mosby. 2013.

[8] Wong, D. et al. Pediatric Nursing Textbook Wong. Edition 6. Vol 2. Jakarta: EGC. 2009.

[9] Gunawan, et al. Stress and Immune System of the Body: A Psychoneuroimmunology Approach, Journal of Professional Education of the UGM Faculty of Medicine Yogyakarta. 2007.

[10] Kaluas, I, et al. Differences in Puzzle and Storytelling Play Therapy Against Anxiety in Preschool Children (3-5 Years) During Hospitalization of Children in TK.III Hospital. Minisidi in Manado. nursing ejournal. vol. 3. <ejournalunsrat.ac.id/index.php>. 2015.

[11] Supartini, Y. The basic concept of child nursing. Jakarta: Publisher of EGC medical books. 2014.

[12] Mayke S. T. Play, Toys and Games for Early Childhood Education. Jakarta: Gramedia. 2007.

[13] Ilmiasih, R. Influence of Nurse Uniforms: Picture Vests Against Anxiety in Pre-School Children Due to Hospitality. Thesis. University of Indonesia. 2012.

[14] Karlings, M. Child behavior and pain after hospitalization, surgery andanaesthesia.UMEA. University medical dissertation. Sweden. 2009.

[15] Supartini, Y. Text book for Basic Concepts of Child Nursing. Jakarta: EGC. 2008.

[16] Elfira, E. The effect of play therapy with techniques tells the story of anxiety due to hospitalization in pre-school children in the child care room at H. Adam Malik General Hospital in Medan. Thesis, University of North Sumatra. http://repository.usu.ac.id/ handle / 123456789/24484. 2011.

[17] James, S.R. \& Ashwill, J.W. Nursing care of children: Principles \& practice. ( $3^{\text {th }}$ ed). St Louis: Saunders Elsevier Inc. 2007.

[18] Roohafza, H., Pirnia, A., Sadeghi, M., Toghianifar,N., Talaei, M \& Ashrafi, M. Impact of nurses clothing on anxiety of hospitalised children. Journal of Clinical Nursing, 18, 1953-1959. 2009.

[19] Spence, S.H. Dkk. The structure of anxiety symptoms among preschoolers. Behaviour research and therapy. 2001.

[20] Stubbe, D. A. A Focus on Reducing Anxiety in Children Hospitalized for Cancer and Diverse Pediatric Medical Disease Through a Self-engaging Art Therapy. 2008.

[21] Hurlock. E. B. Child Development. Jakarta: Erlangga. 2011.

[22] Nursalam. Research Methodology Nursing Science: A Practical Approach: Jakarta: SalembaMedika. 2013.

[23] Cooke and Rudolph. Rudolph's pediatric first edition. The Mc. Graw, Hill Compnies. 2009.

[24] Nursalam, et al. Infant and child nursing care (for nurses and midwives). Issue 1. Jakarta: Salemba Medika. 2005.

[25] Fradiyanto, I. Effect of wax play therapy on decreasing anxiety levels in preschoolers who have 
undergone hospitalization in RSUD dr. Soedarso Pontianak. Essay. Muhammadiyah University. Surakarta. Vol 1. 2014.

[26] Haruyama S. The Miracle of Endorphin. Bandung: PT. Mizan Library. 2011.

[27] Suryabrata, S. Personality Psychology. Jakarta: Raja Grafindo Persada. 2012. 